\title{
ERRATA
}

Yue Wang • Kazuya Minato • Ikuho Iida

\section{Mechanical properties of wood in an unstable state due to temperature changes, and analysis of the relevant mechanism IIl: effect of quenching on stress relaxation of chemically modified woods}

Published online: March 3, 2007

Errors appear in the next-to-last sentence of the second paragraph in the subsection "Acetylation and formaldehyde treatment" in "Materials and methods." The sentence should read as follows: "The values of WG for formaldehyde-treated wood were $0.59 \%-5.42 \%$ and those for acetylated wood were $16.7 \%-24.5 \%$."

In addition, an incorrect version of Fig. 2 was published. The correct figure appears here.

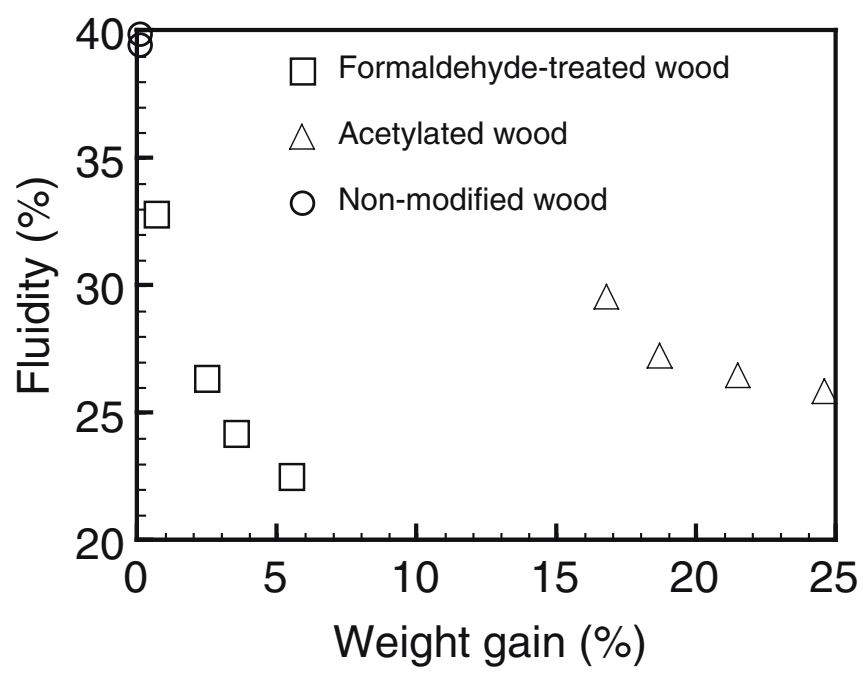

Fig. 2. Effect of chemical modifications on fluidity of quenched wood

The online version of the original article can be found at http://dx.doi.org/10.1007/s10086-006-0831-2

Y. Wang $\cdot$ K. Minato $\cdot$ I. Iida $(\bowtie)$

Research Division of Agricultrue, Graduate School of Kyoto

Prefectural University, Kyoto 606-8522, Japan

Tel. +81-75-703-5639; Fax +81-75-703-5639

e-mail: i_iida@kpu.ac.jp 